The book makes instructive reading for all interested in economic minerals and their uses, and is particularly informative, for example, on the uses to which some of the rarer metals are now being put. It will prove invaluable to the industrial chemist, for whom it is especially intended; but should also be useful, as a reference book, in those technical and other educational establishments where the curriculum includes the economic applications of chemistry and mineralogy.

V. A. Eyles

\section{THE FIRST COLONIZATION OF BRITAIN BY FARMERS}

The Neolithic Cultures of the British Isles A Study of the Stone-using Agricultural Communities of Britain in the Second Millennium B.C. By Prof. Stuart Piggott. Pp. xix $+420+12$ plates. (Cambridge: At the University Press, 1954.) $70 s$. net.

WITH the aid of soberly scientific imagination and historical insight, the fragmentary results of fossilized behaviour that constitute the archro. logical record have been here interpreted by Prof. Stuart Piggott as documenting the first colonization of the British Isles by farmers, the adaptations of their exotic cultures to the insular environment and the reactions of surviving Mesolithic 'natives' to the impact. The result is no tedious catalogue of invasions (though to explain the facts the author has to postulate at least six distinct bands of "Neolithic" immigrants apart from several groups of "Beaker folk"), but genuine history-at least economic history -as concrete as the limitations of archrological data allow; for example, the lively account of the autumn round-up of stock in "causewayed camps" is no product of fancy, but a legitimate inference from observed phenomena that have been factually described. For the archæological data are here assembled, classified and presented so fully that. a sceptical reader can discern possible inconsistencies even in statements that the author accepts (for example, a "cremation" of which no burnt bone survives; the account of the Baltinglass cairn is vitiated only by a defect in the published plan that Prof. Piggott justifiably followed) and illustrated by figures and maps that are artistic as well as instructive. As a result, Prof. Piggott's work is a standard and indispensable source-book from which all further work on the problems of the period must start. For problems still are left.

Most of the material so exhaustively surveyed has been accumulated during the past twenty-five years, much in the past decade, while some of the most reliable data are due to the author's own excavations at well-selected sites. At the same time, Prof. Piggott has extracted every scrap of serviceable information from older accounts of digs into flint mines and long barrows. The interpretative concepts are likewise novel and original. As to chronology, the book's sub-title will advise the reader that the Neolithic period surveyed does not begin, as it would have $a_{0}$ quarter of a century ago, with the end of the Pleistocene. Its end will still surprise many readers ; "Neolithic" for Piggott does not end, as has been assumed for the past fifty years, with the advent of "the Beaker folk". Though typologically early bronze weapons are doubtless found, albeit very rarely, in their graves, and exports on the Continent of Europe imply even the contemporary existence of a school of local metallurgy at least in Ireland, societies here described undoubtedly continued to maintain purely Neolithic traditions after the Beaker invasion and down to the rise of the Wessex culture. After all, on Montelius's system for: Scandinavia, Neolithic IV coincides with Bronze Age I, and a similar usage would be legitimate here.

The Beaker invaders are not here treated among "the stone-using agricultural communities of Britain"; they are excluded not as consumers of metal ware, but as exponents of "the novel rite of individual burial", while "some form of collective burial appears to be characteristic of all the neolithic cultures here described". Therewith, "collective burial" too is given a novel sense, being applied to cremations interred in individual graves, if these are grouped in closed cemeteries, as much as to the burial of several persons' remains in a common tomb, to which latter rite the term had hitherto been restricted. Admitted cases of individual burial in "Neolithic" cultures are explained as due to the influence of the Beaker invaders, even though at Linch Hill such a burial was stratigraphically prior to an interment with a Beaker.

Original, too, and fruitful is Prof. Piggott's concept of "Secondary Neolithic cultures", in which such elements as "can be regarded as intrusive" are "inextricably mixed with other features which have a long local ancestry in Mesolithic cultures", whereas the Primary cultures, associated with the first farmercolonists, should represent "a virtual transfer of French early Neolithic traditions to this country". But in the sequel it is suggested that the distinctive secular monuments of the colonists-the "causewayed camps" (which are really cattle corrals)together with the techniques of skin-dressing illustrated in them, may be due to "intermixture with indigenous hunter-fishers", while their long barrows might have been as appositely compared to Megalithic tombs in north-east Germany as to the tertres allongés of Morbihan. On the other hand, Secondary Neolithic pottery of the Peterborough elass is so like the pitted ware of Sweden that the author inclines to regard its "appearance as an indication of settlement in south-east England of people arriving by sea from Scandinavia". Now, since the book went to the press (in 1951), Becker has shown that the makers of pitted ware played just the same part in the distribution of flint axes in Scandinavia as Secondary Neolithic folk played in Britain in the remarkable trade in axes from the Langdale, Penmaen Mawr and Antrim factories which systematic petrological examination has revealed recently, but in time for description by Prof. Piggott. This three-year interval between composition and publication must also be remembered in connexion with other comparisons with North European material. The author has just failed to translate the older Danish-Swedish chronological terminology into that adopted during the past five years, and consequently seems to have inverted the chronological relations between the Beacharra $C$ and Peterborough phases here, in so far as these are deduced from North European parallels. In the precocious science of prehistoric archæology progress is so rapid and publication has become so slow that any book must be to some extent out of date when it is issued. Prof. Piggott has written an exhaustive and authoritative account of Neolithic Britain as it appeared in 1951. V. G. CHILDE 